\title{
XXXV. Experiments on electrolysis-Part I. Change of density of the electrolyte at the electrodes
}

\author{
W.W. Haldane Gee B.Sc. \& H. Holden B.Sc.
}

To cite this article: W.W. Haldane Gee B.Sc. \& H. Holden B.Sc. (1888) XXXV. Experiments on electrolysis-Part I. Change of density of the electrolyte at the electrodes, Philosophical Magazine Series 5, 25:155, 276-283, DOI: $10.1080 / 14786448808628186$

To link to this article: http://dx.doi.org/10.1080/14786448808628186

曲 Published online: 29 Apr 2009.

Submit your article to this journal $\longleftarrow$

Џ Article views: 2

Q View related articles $\square$ 
of geological time is not so great as is ordinarily assumed. There is no reason to believe that the time required for the deposit of thick strata must be longer, proportionally to the number of feet, than that required for the deposit of thin. If the thick strata had been laid down in waters as deep as the average of the deeper areas of the Atlantic, vast time might perhaps have been required; but there is no evidence for such depths having ever been attained to the east of the present line of 100 -fathom soundings off the British Islands. Even the Carboniferous and Cretaceous Limestones do not prove the existence of such deep waters; they only show that at these periods there was long-continued subsidence and continuous deposit in clear water. Prof. Huxley's homotaxis is thus applied within the compass of the European area; and, if the views embodied in this table are correct, the careful correlation of strata which has given so much occupation to geologists loses much of its importance. The palæontological differences are the variations of inhabitants of adjacent zoological areas on a sea-floor inclining westwards.

XXXV. Experiments on Electrolysis.-Part I. Change of Density of the Electrolyte at the Electrodes. By W. W. HaLdane GEE, B.Sc., Assistant Lecturer in Physics, and H. HoLden, B.Sce, Bishop Berkeley Fellow in Physics, of the Owens College, Manchester**

WHILST studying some electrolytic polarization phenomena with palladium electrodes in dilute pure sulphuric acid, a liquid was seen, after a reversal of the current, to flow downwards in streaks from the anode. Not being able to find any reference to the formation of streaks, for whose appearance the reversal of the current was necessary, it was decided to investigate their character. Further, it was thought that the occluded hydrogen might, on reversal of the current, unite with the nascent ion liberated at the anode, and thus effect chemical changes of an interesting character.

Some little care in observation and adjustment of the light

* Communicated by the Physical Society : read February 25, 1888.

This is the first of a series of papers on Electrolysis and Electrolytic Polarization, descriptive of experiments made, during last year, at the Owens College Physical Laboratory. An abstract of the experiments made, to the end of August 1887, was subenited to the British Association Meeting at Manchester. We desire to acknowledge the assistance received up to that time from Mr. C. H. Lees, B.Sc., Derby Mathematical Scholar of the Owens College. His cooperation has since been discontinued, owing to absence at Strasburg. 
is necessary in order to see the streaks, which, like the surrounding electrolyte, are colourless, and are only visible on account of the difference between their index of refraction and that of the main bulk of the electrolyte. A vessel with parallel sides of good plate-glass was employed, and a mirror used to reflect light obliquely into the cell. The arrangement which has been found to be most convenient is shown in the figure, and consists of a cell made of two pieces of plate-glass about 15 centim. square. A piece of india-rubber, 25 centim. long and 3 centim. square section, is bent in a semicircular form and clamped between the two glass plates by means of four iron screw-clamps. In this way a water-tight cell, about 1.5 centim. broad, is obtained which may readily be taken to

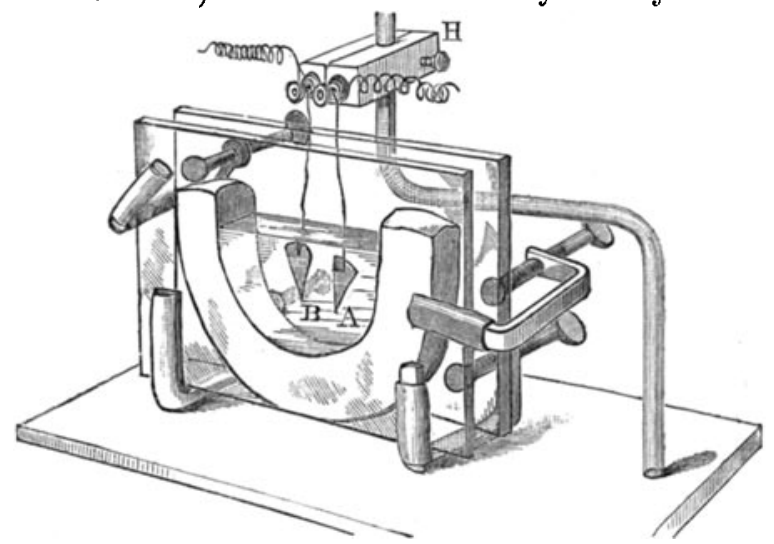

pieces for the purpose of cleaning. The electrodes have usually consisted of two pieces of palladium, about 05 centim. thick and with a surface of 5 square centim., fastened to platinum wires and supported by means of a convenient electrode-holder.

Streaks obtained in dilute pure Sulphuric Acid.

The electrodes were first heated to redness in order to drive out any occluded gas, and then cleaned by means of glasspaper. They were then placed, by means of the electrodebolder $\mathrm{H}$, in the electrolytic cell containing dilute pure sulphuric acid. The current was sent from one electrode (A) to the other (B), which is thus the kathode, for a certain time and then reversed. On reversal no gas appears at first from $\mathrm{B}$, which is now the anode, but streaks resembling a dense liquid are with careful observation seen flowing downwards from this electrode. After a time, depending on the size of the electrodes, the strength of the current, and its duration in

Phil. Mag. S. 5. Vol. 25. No. 155. April 1888. U 
the first direction, evolution of gas at $B$ begins, and the streaks simultaneously cease to be visible. The streaks are to be seen streaming from one electrode only at a time, and always descend from that palladium electrode which first serves as kathode and then as anode.

When platinum electrodes are substitnted for the palladium ones, we have not been successful in obtaining the streaks; it is, however, only necessary that one of the electrodes should be palladium in order to obtain the streaks.

An experiment was made in order to ascertain the part which the reversal of the current plays in the formation of the streaks. The current was sent in one direction through the electrolyte, the palladium electrodes then taken out, washed, and their surface cleaned with glass-paper. On now reversing the current and replacing the electrodes, the streaks are quite as evident as if the electrodes had not been taken out. But if, on taking the electrodes out, they are heated to redness instead of merely having their surface cleaned, on replacing: them and reversing the current the streaks are not seen, and gas appears immediately from the anode. We concluded from this experiment that the function of the current in the first direction was to fill with hydrogen that electrode at which the streaks appear in the second direction of the current; and that the reason why, after a time, the streaks ceased to be visible, and simultaneously gas began to be evolved at the anode, was that by this time all the occluded hydrogen had been used up. It was therefore thought probable that the streaks were formed by a combination of the occluded hydrogen with the ion (either $\mathrm{SO}_{4}$ or some of its components, such as oxygen) which is liberated at the anode in the second direction of the current. The theory that the streaks were composed of concentrated sulphuric acid seemed open to great objections ; for we know that concentration takes place at the anode in dilute sulphuric acid without a reversal of the current, and also does not depend on the use of palladium electrodes; but the streaks are, as is shown above, only to be obtained after a reversal of the current, and are not to be obtained with platinum electrodes. It was therefore decided to test, as far as practicable, other possible combinations, such as hydroxyl (the streaks cannot be composed of water, for they are denser than the surrounding electrolyte), a salt of palladium, \&c.

\section{Testing for Hydroxyl.}

The palladium electrodes used were rectangular strips, about 2 centim. long and 3 centim. broad, placed vertically in 10 . 
per-cent. sulphuric acid. For the purpose of collecting the streaks a capillary glass tube had one end blown out into the shape of a small funnel, and was bent so that it could be lowered into the electrolyte with the finger pressed on the upper end, which projected from the cell, until the funnel part was immediately below the electrode. After a reversal of the current the funnel part was placed in this way under the anode, from which the streaks were flowing. The finger was then removed from the top end of the tube, and the funnel acted as a reservoir for the denser liquid flowing from the anode. As soon as gas appeared at the anode the finger was replaced on the top end of the tube, the latter being then removed and its contents emptied into a test-tube. This proceeding was repeated many times (at least fifty), and the total liquid collected was tested for hydroxyl by the addition of a few drops of a solution of titanic acid in strong sulphuric acid. No trace of a coloration could be perceived, and thus the presence of hydroxyl was not proved *.

* The test, which is a delicate one, has been greatly employed by Richarz in his experiments on the mode of appearance of hydroxyl at the anode in sulphuric acid (Wied. Ann. xxxi. p. 912, 1887). He concludes that the appearance of hydroxyl at the anode is caused by the purely chemical decomposition of the "Ueberschwefelsäure" (Berthelot's $\mathrm{S}_{2} \mathrm{O}_{7}+$ $\mathrm{H}_{2} \mathrm{O}$ ), which is first formed there. Traubs, Berichte der deut. chem. Gesell. xriii. p. 3348 (1888) gives the equation for this decomposition as

$$
\mathrm{S}_{2} \mathrm{O}_{6}\left(\mathrm{O}_{2}\right) \mathrm{H}_{2}+2 \mathrm{H}_{2} \mathrm{O}=2 \mathrm{H}_{2} \mathrm{SO}_{4}+\mathrm{HI}_{2}\left(\mathrm{O}_{2}\right) \text {. }
$$

Richarz confirms Berthelot's statement that no hydroxyl is formed at the platinum anode unless the strength of the acid is above 60 per cent. As we obtained the strealss in 10-per-cent. acid, the above fact lends additional strength to the view that the streaks are not hydroxyl. They might consist of $\mathrm{H}_{3} \mathrm{~S}_{2} \mathrm{O}_{8}$ (Ueberschwefelsäure), which Berthelot has shown to be a minor secondary product formed during the electrolysis of sulphuric acid, whether dilute or strong (see Ann. de Chim. et de Mhys. xiv. 1878, and xxi. 1880). The quantity so formed at a platinum anode is small, and would apparently be still smaller at a palladium anode charged with hydrogen if the following reasoning be accepted. Let us first consider the case of an anode uncharged with hydrogen. Assuming that the ion liberated at the anode is $\mathrm{SO}_{4}$, the simplest hypothesis to account for the secondary reactions is that part of the $\mathrm{SO}_{4}$ combines directly with the $\mathrm{H}_{2} \mathrm{SO}_{4}$ of the electrolyte to form $\mathrm{II}_{2} \mathrm{~S}_{2} \mathrm{O}_{3}$, whilst the remainder of the $\mathrm{SO}_{4}$ (probably by far the greater part) acts on the $\mathrm{H}_{2} \mathrm{O}$ of the electrolyte, forming $\mathrm{H}_{2} \mathrm{SO}_{4}$ and liberating $\mathrm{O}$. Should, however, the anode be charged with $\mathrm{H}$, the $\mathrm{SO}_{4}$ would have an additional tendency to combine directly with the $\mathrm{H}$, forming $\mathrm{H}_{2} \mathrm{SO}_{4}$. This tendency would probably greatly exceed the other two, so that if sufficient occlnded $H$ be present, it would be expected that neither $\mathrm{O}$ would be liberated, nor $\mathrm{H}_{2} \mathrm{~S}_{2} \mathrm{O}_{3}$ formed. It is known that there is no evolution of $O$ under these conditions; and it would be interesting to estimate the relative amounts of $\mathrm{H}_{2} \mathrm{~S}_{2} \mathrm{O}_{8}$ produced at a palladium anode when charged and when uncharged with $\mathrm{H}$. The $\mathrm{H}_{2} \mathrm{~S}_{2} \mathrm{O}_{8}$ could be quantitatively determined by the method used by Richarz (loc. cit. p. 917). 


\section{Testing for Palladium Salts.}

A supply of the liquid having been obtained by a similar process to the above, a solution of potassium iodide was added to it, but no evidence of the presence of palladium was obtained.

\section{Streaks obtained in Phosphoric Acid.}

Similar streaks were obtained in solutions of pure orthophosphoric acid by adopting exactly the same procedure as with sulphuric acid.

\section{Streaks obtained in Caustic-Soda Solution.}

In this case also streaks were obtained descending from one of the electrodes, but the conditions necessary for their appearance are very different to those in the case of sulphuric and phosphoric acids. No previous reversal of the current is necessary, and the streaks descend from the kathode immediately the current is passed. The gas (hydrogen) formed at the kathode is at first absorbed, and the streaks are seen to descend as long as the absorption takes place; but, when gas begins to be evolved briskly, the streaks disappear. By very careful observation it is seen that the liquid of which the streaks are composed is still formed, but is carried up in the current of gas to the surface of the electrolyte, from which it rebounds, giving the electrolyte round the kathode the peculiar wavy appearance which accompanies the incomplete mixing of two liquids of different densities, such as two strengths of the same solution.

\section{Explanation of the Caustic-Soda Streaks.}

This experiment led us to infer that the streaks in the caustic-soda solution are composed of concentrated alkali, which is known to be formed at the kathode, and that the absence of evolution of gas from that electrode is a necessary condition for their appearance and steady downward flow. The part played by the palladium in the formation of the streaks is, according to this theory, that of absorbing the hydrogen, which otherwise, in escaping from the electrode, would carry the concentrated solution along with it to the surface and thus prevent the formation of the streaks.

\section{Explanation of Streaks in general.}

Since in acids concentration occurs at the anode, the descending streaks, if seen at all, should be seen at that electrode. But taking sulphuric acid as an instance, oxygen is given off at the anode, and the palladium cannot retain it sufficiently 
to stop its evolution, and thus the concentrated acid will be carried up by the current of oxygen and escape observation. But if the electrode has been filled with hydrogen by previously serving as kathode, the evolution of oxygen on reversal of the current is prevented either by its direct union with the occluded hydrogen, or by the union of the ion $\mathrm{SO}_{4}$ with the hydrogen. No gas being evolved, the concentrated acid is able to flow downwards in streaks. This explanation is borne out by the experiments with sulphuric acid detailed above, in which it was seen that, on placing freshly-heated palladium electrodes in sulphuric acid, gas is immediately evolved at the anode; but if that electrode has been previously filled with hydrogen, the oxygen, on reversal of the current, does not appear for some time at the anode, and the streaks are visible during this period.

Concentration of the solution at one electrode is accompanied by a weakening of the solution at the other electrode. 'Therefore, as in acids the weakening takes place at the kathode (at which the gas is absorbed), we should expect to see streaks ascending from that electrode without a previous reversal of the current. On trying the experiment with palladium electrodes placed horizontally in dilute sulphuric acid, this supposition is found to be warranted. The reason why the streaks ascending from the kathode were not seen in our earlier experiments is, that the electrodes had been placed vertically with their top edges a little below the surface of the electrolyte, and so the weakened solution in ascending had naturally clung to the surface of the electrode and thus escaped detection.

The late Professor Christiani (in a work* to which we shail refer more fully in a subsequent paper) gives three instances in which he observes streaks from the electrodes, but does not offer any explanation of their mode of formation. He cites the cases of zinc electrodes in concentrated zinc sulphate and copper electrodes in concentrated copper sulphatef. In these cases, without a previous reversal, he observed streaks descending from the anode and ascending from the kathode at the same time. These results are evidently in accordance with the theory proposed above: no gas js given off at either electrode, and so the concentraterl solution is allowed to descend in streaks from the anode and ascend in streaks from the (horizontal) kathode.

* "Ueber irreciproke Leitung electrischer Ströme," 1876, R. Friedländer ; Wied. Elect. ii. p. 727.

+ Christiani, loc. cit. p. 100. 


\section{Change of Density of the Electrolyte at the Electrodes.}

Another confirmation is given by the behaviour of potassium sulphate during electrolysis. After a current has been passed in the same direction through potassium sulphate, it is found, on testing with litmus paper or by cautiously adding litmus solution, that the bottom strata of liquid have become alkaline and the top strata acid, the solution being originally neutral. It follows from this that the alkaline solution produced at the kathode is denser than the electrolyte, which itself is denser than the acid solution produced at the anode. Therefore, according to theory, the streaks, if seen at all, should descend from the kathode and ascend from the anode. This is fully borne out by experiment. Starting with freshly-heated palladium electrodes, on putting on the current we immediately see the streaks descending from the kathode; and after a reversal of the current other streaks may simultaneously be detected rising from the anode.

The best conditions for seeing the streaks seem to be:-

(1) a horizontal electrode of small surface*,

(2) a strong current,

(3) no evolution of gas.

The conditions (2) and (3) are incompatible with the use of platinum electrodes in dilute sulphuric acid: it is quite possible, however, that even in this case matters might be so adjusted that some trace of the formation of the streaks could be detected. In the case of platinum electrodes in solutions of sulphates of metals which do not act readily on water, such as zinc, copper, iron, \&c., the metal will be deposited and no gas evolved at the kathode, and thus streaks of the weakened solution can be seen at that electrodet.

A direct proof that the streaks were formed of concentrated acid might be thought possible, in the case of sulphuric acid, on consideration of the following circumstances:-

(1) When strong sulphuric acid is dropped into dilute sulphuric acid, the strong acid sinks to the bottom of the containing vessel and remains undiffused for a considerable period.

(2) If collecting-vessels are placed under the electrodes and an arrangement fitted up by which the current may be periodically reversed, say every minute, the streaks will be formed at the electrodes and will stream into the collecting-vessels.

* A vertical electrode may be used with advantage if it is well below the surface of the electrolyte and if it is suspended by a horizontal wire, so that the view of the electrolyte above and below it is not interrupted. An angular electrode is very convenient, as the liquid flows most readily from points.

$\dagger$ Christiani noted the streaks with platinum electrodes in ferrous sulphate. 
(3) If we now titrate with standard caustic-soda solution equal volumes of the liquid in the collecting-vessels and of the main bulk of the electrolyte, we ought to find that the former is the more acid.

It may, however, be noticed that, assuming the streaks were not concentrated acid, we should collect by this arrangement, not only the streaks, but also some of the concentrated acid which is formed at the anode. Thus, even if the acid in the collecting-vessels did become stronger, it would scarcely prove that the streaks were the cause of this*.

From the experiments detailed above, though direct proofs are apparently not available, we may draw the following general conclusions:- That when gas is not evolved at an electrode, streaks are formed there. These are due either to a concentration or weakening of the electrolyte, as in the case of solutions of acids and alkalies and some salts (such as zinc sulphate); or, in the case of other salts (such as potassium sulphate), to a chemical change in the electrolyte, yielding at one pole alkali and at the other pole acid, producing solutions of different density to the electrolyte. When gas is not evolved at an electrode these changes are still produced, but their effect in producing streaks is destroyed by the evolution of the gas.

In our next paper we hope to describe some experiments in which these effects become of great importance in changing the resistance of the electrolyte.

\section{On a Modified Water-dropping Infuence-machine.} By Professor Silvanus P. Thompson, D.Se. $\uparrow^{\dagger}$

THE ordinary form of water-dropping influence-machine, 1 as devised by Sir William Thomson $\ddagger$, possesses some inconveniences : it requires a double jet of water and special arrangements for high insulation. A simpler form, requiring but one water-jet and mere silk strings (well paraffined) as insulators, has been found by the author to give far less trouble, and to work well for lecture demonstrations.

* Some observations have been made by this method, but the results have not been very definite. We have designed an automatic commutator which will reverse the current at intervals of 15, 30, or 60 seconds. This arrangement will enable us to collect more easily the substance forming the streaks.

$\uparrow$ Communicated by the Physical Society: read January 28, 1888.

$\ddagger$ Proc. Roy. Soc. June 20, 1867 ; and Reprint of Papers on Electrostatics, p. 321 . 